\title{
A novel device for controlling brushtail possums (Trichosurus vulpecula)
}

\author{
Helen Blackie ${ }^{1,2^{*}}$, Jamie MacKay ${ }^{1,3}$, Brent Barrett ${ }^{1}$, Shane Inder $^{4}$, Duncan MacMorran ${ }^{2}$, \\ Jennifer Bothwell ${ }^{1}$, Mick Clout ${ }^{3}$, Charles Eason ${ }^{1,5}$ \\ ${ }^{1}$ Centre for Wildlife Management and Conservation, Lincoln University, PO Box 84, Lincoln 7647, New Zealand; \\ ${ }^{2}$ Connovation Ltd, PO Box 58613, Botany, Auckland 2163, New Zealand \\ ${ }^{3}$ Centre for Biodiversity and Biosecurity, University of Auckland, Private Bag 92019, Auckland 1142, New Zealand \\ ${ }^{4}$ Industrial Design and Innovation Lab, Faculty of Design and Creative Technologies, Auckland University of Technology, \\ Auckland 1145, New Zealand \\ ${ }^{5}$ Cawthron Institute, Private Bag 2, Nelson 7042, New Zealand \\ *Author for correspondence: (Email: helen.blackie@boffamiskell.co.nz)
}

Published online: 28 August 2015

\begin{abstract}
Pen and small-scale field trials have been completed on a new, long-life, resetting toxin delivery system for brushtail possums (Trichosurus vulpecula). Devices are designed to attract and control possums over long periods of time with minimal input and maintenance. The units are species-specific, lightweight, environmentally robust, and have the ability to control 100 possums before requiring servicing. Devices dispense a measured dose $(0.8 \mathrm{~g})$ of a palatable gel containing $12.5 \%$ zinc phosphide $\left(\mathrm{Zn}_{3} \mathrm{P}_{2}\right)$ onto a possum's abdomen. Pen trial results demonstrated that after receiving a measured dose from these devices, $89 \%$ of nine possums groomed the gel from their fur, ingested it and died. The average time to death following ingestion of a lethal dose of zinc phosphide was 4.6 hours, a comparatively short timeframe compared to other control tools (specifically sodium fluoroacetate, cholecalciferol or brodifacoum). A small-scale field trial deploying 11 devices at 100-m intervals was run in an 11-ha mountain beech (Fuscospora cliffortioides) forest site. A sample of ten possums in the vicinity of these devices were collared with VHF-mortality sensors and, of the nine individuals with known fates, eight were killed shortly after interacting with a resetting delivery system.
\end{abstract}

Key words: Population control; resetting toxin delivery system; zinc phosphide; vertebrate pesticide

\section{Introduction}

In New Zealand, the introduced brushtail possum(Trichosurus vulpecula) continues to damage natural forest ecosystems and, as a vector of bovine tuberculosis, threatens the beef, venison and dairy industries (Coleman \& Caley 2000; Payton 2000; Cowan 2005). Except in a few areas where eradication or exclusion is feasible, population management is possible only through effective and ongoing control(Cowan 2005). However, sustained control in large, mainland areas is costly, and success may be influenced by factors such as the aversion behaviour of possums as a result of sub-lethal poisoning (O'Connor \& Matthews 1995; Hickling et al. 1999; Ross et al. 2000), the inadequate distribution of bait (Morgan et al. 1996), or nontarget species removing baits (Eason \& Spurr 1995; Morriss et al. 2012). As a result, some possums may survive both initial and maintenance control operations (Henderson et al. 1999; Morgan \& Hickling 2000). Additional difficulties may exist owing to public opposition to certain control tools, such as the aerial distribution of sodium fluoroacetate (1080), which has led to increased use of ground-based control operations, particularly bait stations, paste baits and trapping (Thomas 1994; Henderson et al. 1999; Fitzgerald et al. 2000).

Recently, new toxins for possum control, such as sodium nitrite and zinc phosphide, have been registered in New Zealand (Eason et al. 2010, 2013; Blackie et al. 2014). To maximise the benefits of these new toxins, there has also been concurrent development of resetting delivery systems (RDS), which can offer sustained control over long timeframes with safety as a prime consideration (Blackie et al. 2014). The concept of resetting poison delivery devices for possums was first suggested by McDonald et al. (1999), who developed prototype units of a system in which the bait remained potent over time, while removing risks to non-target species or of sub-lethal dosing. Unfortunately, these devices were unreliable and never progressed to field application.

In a multidisciplinary collaboration, we have developed a possum-specific resetting toxin delivery system, capable of delivering 100 measured doses per unit, and which can be deployed in the field for the continuous control of possums. This device is a tree-mounted unit that requires a possum to stand on a weight-activated platform and simultaneously touch a lured upper trigger (Fig. 1), causing a measured dose $(0.8 \mathrm{~g})$ of toxin-containing gel to be dispensed by a spray mechanism onto the possum's abdomen. A palatable paste containing $12.5 \%$ zinc phosphide $\left(\mathrm{Zn}_{3} \mathrm{P}_{2}\right)$ was developed for incorporation into this system. Zinc phosphide paste was approved for use as a possum control agent in New Zealand by the Environmental Protection Authority (EPA) in August 2011 (Eason et al. 2013). It has been used overseas as a vertebrate toxic agent for rodents and other animal pests for several decades, particularly in the United States and Australia. Zinc phosphide has a comparatively low risk of secondary poisoning and a lack of environmental persistence (Eason et al. 2013).

Our main aim was to develop a long-life, resetting delivery system to provide continuous and consistent on-going possum control. This system could be used to complement current control methods and potentially to assist with reinvasion problems. This paper describes the development of this new system, from initial formulation of a toxic gel through to a short-term, proof-of-concept field trial. 


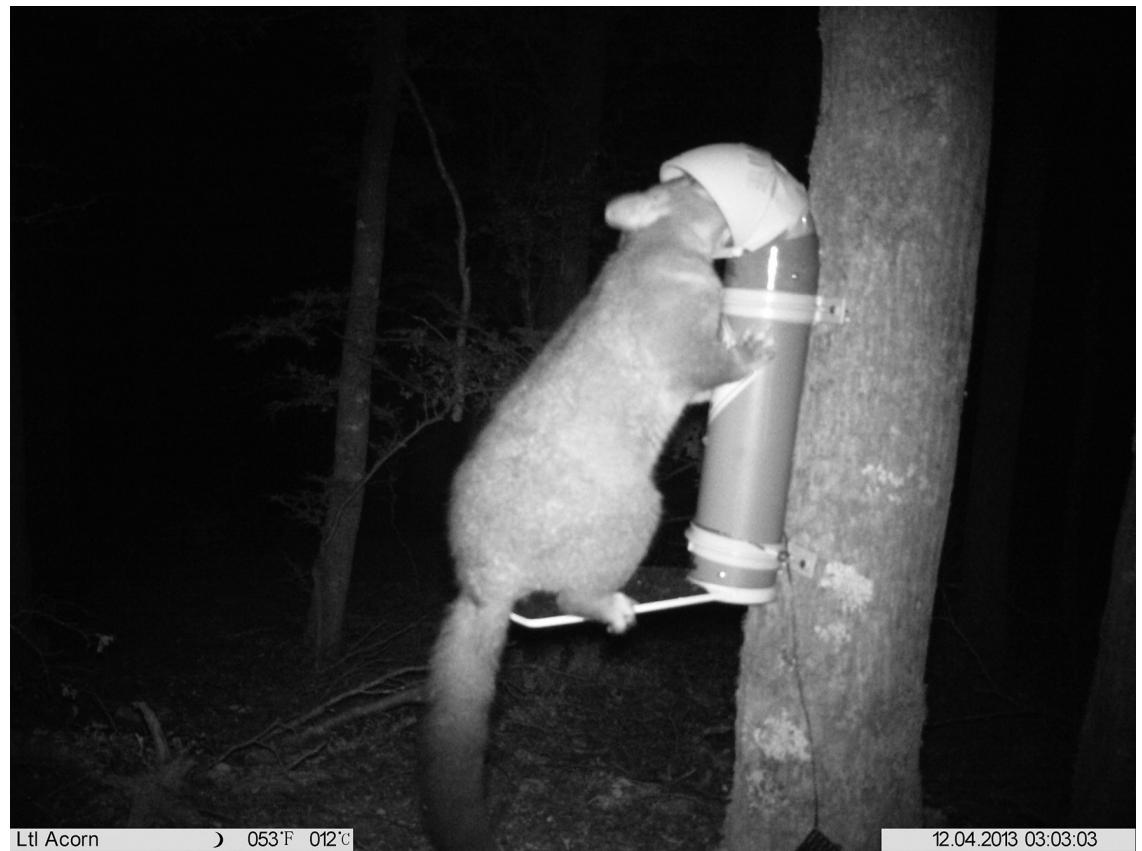

Figure 1 Brushtail possum, Trichosurus vulpecula, interacting with the resetting delivery system (RDS). The lower platform is a weight-activated trigger (set to $>1 \mathrm{~kg}$, but adjustable). The upper trigger has a long-life lure which must simultaneously be touched along with weight activation for the unit to dispense a measured dose of a zinc-phosphide gel.

\section{Materials and methods}

\section{Pen trials}

For all trials, wild-caught possums were anaesthetised on arrival and sexed, weighed, health-checked, and ear-tagged. Possums were housed in individual enclosures (approximately $1.2 \times 2.5 \mathrm{~m}$ ), each containing a large hessian hanging sack and wooden box as denning sites, and tree branches and vegetation for enclosure enrichment. Possums were acclimatised for a minimum period of 7 days before trials started. Throughout acclimatisation and during trials, possums were fed a selection of grains and fresh vegetables, and water was available ad libitum.

Initial trials focused on developing a palatable gel that would be successfully groomed (i.e. cleaned from the fur and ingested) by possums if dispensed onto their bodies. The first step in this process was establishing the optimal placement for a dose of this gel and analysing grooming behaviour. Thirtysix possums were manually dosed with $5 \mathrm{~g}$ of a palatable paste using a measured syringe in one of three locations (their abdomen, lower back or between their shoulders). Following application of paste, possums were observed by researchers, and the number of possums that groomed the paste and time (minutes) until its full removal were recorded.

Nine wild-caught possums (from Hororata, Canterbury) were used in the toxic pen trial. A single RDS unit and three video surveillance cameras were set up in each enclosure. These cameras allowed researchers to record possum interactions with units and subsequent behaviour, including the time at which the systems were triggered, onset of grooming behaviour and symptoms, and estimated time until death. Possums were also manually checked by researchers hourly throughout the night following onset of symptoms, according to Animal Ethics Committee requirements. Possums were not checked more frequently than hourly to avoid researchers influencing their behaviour.

\section{Field trials}

Non-toxic field trials of the resetting delivery systems took place in the Coatesville Scenic Reserve, Auckland ( $36^{\circ} 42^{\prime} \mathrm{S}$, $\left.174^{\circ} 38^{\prime} \mathrm{E}\right)$, a 12-ha area of mixed podocarp-broadleaf forest surrounded by pasture. An initial trial of two protoype RDS units (spaced $400 \mathrm{~m}$ apart) was done in May 2012, and a second trial with a later version of two units in August 2013. In both trials, two motion-detecting cameras were trained on each RDS to monitor interactions of possums and non-target species. In both trials the RDS units were left in place for 7 days. For these trials a biomarker $(0.5 \%$ Rhodamine B; Fisher 1999) was included in the gel spray formulation. Two weeks after deployment, possums within the area were live-trapped, anesthetised and checked for signs of Rhodamine B staining on their abdomens. Two whiskers were collected from each captured individual and examined under UV microscopy to determine whether the spray gel had been ingested. If the animal had consumed the gel, Rhodamine B bands were visible.

A small-scale toxic field trial took place during December 2013 to January 2014 at the Cass Mountain Research Area (CMRA), near Cass Village on the Canterbury side of Arthurs Pass, New Zealand ( $\left.43^{\circ} 01^{\prime} \mathrm{S}, 171^{\circ} 47^{\prime} \mathrm{E}\right)$. This trial location was selected due to its high level of controlled access (no public access is permitted and only approved research activities may occur on site). The treatment site, where RDS units were deployed, covered two pockets of mountain beech (Fuscospora cliffortioides) forest within the CMRA, over c. 11 ha. The surrounding vegetation was dominated by shrubs, including matagouri (Discaria toumatou), tauhinu (Ozothamnus leptophyllus), mingimingi (Coprosma propinqua) and Hebe venustula.

Three weeks before the deployment of RDS units, 28 live-capture traps were set within and surrounding the beech forest treatment area at 50-m intervals. Traps were set for 4 nights using an apple and a flour lure. Captured possums were anaesthetised with halothane gas, ear-tagged, sexed and weighed, and a small transmitter collar (c. $60 \mathrm{~g}$ ) was attached. Ten possums (four males and six females) were collared. 
Collars consisted of a proximity logger, mortality sensor and standard VHF tracking unit (Wildtech NZLtd, Havelock North, New Zealand). Mortality mode was activated after no collar movement had occurred for a continuous 24-hour period.

Six additional live-capture traps were placed in a shelter belt of radiata pine (Pinus radiata) c. $1 \mathrm{~km}$ from the treatment site, and reset each night for 4 nights. Four additional possums (two females and two males) were captured and collared with VHF mortality collars only. These animals were collared to determine whether they moved into the treatment site following the initial population knockdown there.

Collared possums were checked via theirVHF-signal each day for the first 2 weeks, and then three times a week for the subsequent weeks, to determine if their collars had entered mortality mode. Once a mortality mode had been activated, possums were radio-tracked to their current location and their collars were removed.

Two weeks following completion of live-capturing and collaring, 11 RDS units were deployed at 100-m intervals throughout the mountain beech forest. The units were attached to trees c. $25-35 \mathrm{~cm}$ above ground height according to bestpractice recommendations for bait stations (Morgan 1999), and were left in place for six weeks. Upper triggers were baited with long-life 'solid-state' lure blocks (Connovation Ltd, Auckland), which have been shown in previous field-trials to retain their scent for at least six months and to be highly attractive to possums (MacKay et al. 2014). The lower platform trigger of the RDS was set to activate with a weight exceeding $1 \mathrm{~kg}$. Each device was monitored using motion-detecting cameras (Little Acorn 5210A Trail Cameras, Denmark, WI), to record both possum (collared and non-collared individuals) and non-target species interactions. Additionally, stations were fitted with proximity 'base stations' that recorded time, date, and duration of interactions for each individual fitted with a proximity-collar that came within $15 \mathrm{~m}$ of these stations. Camera footage was analysed to determine whether the interaction recorded by the base station was a successful interaction with the RDS (i.e. one that resulted in the possum being sprayed with the zinc-phosphide-containing gel). Camera footage also showed successful interactions by non-collared individuals. Base station information was remotely downloaded via VHF, and the times when interactions had occurred were related to approximate times at which collars entered mortality mode. Approximate times to death following successful interactions with RDSs were estimated on the basis of these records. Each RDS unit was also fitted with a counter, which displayed the number of times that unit had been triggered. Counters were checked weekly and the number of triggers were recorded for each unit.

\section{Results}

\section{Pen trials}

Possums showed a clear preference for grooming paste dispensed onto their abdomens compared with other body locations. All possums groomed all the gel off their abdomens (with an average grooming duration of 9.7 minutes until full removal). In contrast, only $42 \%$ of possums groomed all gel off when it was dispensed between their shoulders, and no possums successfully groomed gel dispensed onto their lower back. Of the possums that did not successfully groom gel from between their shoulders, $25 \%$ failed to groom at all and $33 \%$ partially groomed the gel. These findings influenced initial design of the RDS, as it was clear that the toxin must be delivered onto the possum's abdomen to achieve successful grooming behaviour.

Eight of the nine possums studied (89\%) died following a successful interaction with the RDS within 24 hours of the devices being placed in their enclosures. Video footage was examined to establish approximate times until grooming, onset of symptoms and death, when possible (the timing of these behaviours could not be sucessfully determined for all individuals). An estimated time until onset of symptoms following grooming of the gel was obtained for four possums, with an average onset of symptoms of just under two hours. Following onset of symptoms, an average time until death of 4.6 hours was approximated for six individuals, ranging from 1.45 hours to a maximum of 12 hours. One possum in this trial received a dose of gel but did not groom within the 24-hour period. No possums were dosed with the toxic gel more than once.

\section{Field trials}

During non-toxic field trials, 23 instances of possums interacting with the devices and then grooming the gel were recorded; as the gel was non-toxic it is likely some of these interactions were by the same individuals. Twenty-four individual possums were live-trapped at the site in the month following the nontoxic trial. Of these, eight individuals $(33 \%$; $95 \%$ binomial CI $16-55 \%$ ) showed signs of Rhodamine B staining on the fur of their abdomens. Subsequent examination of the whiskers of these individuals under UV microscopy confirmed that these possums had ingested the non-toxic gel. There were no recorded instances of any non-target species interacting with the RDS devices. Non-target species sighted at the reserve included kererū (Hemiphaga novaeseelandiae), tūī (Prosthemadera novaeseelandiae), morepork (Ninox novaeseelandiae), and feral cats (Felis catus).

From the toxic field trials, eight of nine collared possums (89\%; CI 51-99\%) died following successful interactions with RDS units within the 6 weeks that the units were deployed. One female possum lost her collar in the 2 weeks before RDS deployment and was removed from the sample. However, this possum was recorded and identified (using ear tags) successfully interacting with a device. She was not seen again at the site (during post-trial trapping or on any motion-detecting footage), so was also presumed dead. Only one of the possums originally collared on-site did not interact with a RDS. This male possum moved extensively during the trial and was frequently tracked to an area several kilometres outside the study site. The remaining eight collared individuals were VHF radio-tracked following activation of the mortality sensor, their bodies located and buried, and collars retrieved. Three non-collared possum carcasses were found during the trial and these were also buried.

Over the 6-week period of deployment there were a total of 41 successful possum interactions with RDS units. The majority of these interactions $(73 \%)$ took place within the first 3 weeks, and the number of interactions gradually declined during the 6 -week trial. Two of the four possums collared in the pine shelterbelt moved into the treatment site 4 weeks after the trial had commenced, and both interacted with devices immediately and died shortly thereafter. At the time these possums moved into the area all but one individual collared at the treatment site had been killed. 
One male in the sample population was recorded receiving two doses of zinc phosphide within one night at two separate RDS stations. All other collared possums received only a single toxic dose. None of the collared possums that survived had known successful interactions with RDS units. The maximum number of sprays dispensed by one unit was nine over the 6-week trial duration, and the minimum was one (with an average of four sprays per unit). Units functioned reliably throughout the trial, and were tested weekly. There were no instances of toxin dispensing when it should not have (for example when small juveniles that did not reach the weight trigger requirement were on the platform). All possums which triggered the system were dosed with the toxic gel.

There were no non-target interactions with units at any stage of the trial. Occasionally, house mice (Mus musculus) were photographed investigating the long-life lures and feral pigs (Sus scrofa) were recorded moving past units but never interacting with them. There were no interactions or apparent interest recorded for any bird species.

\section{Discussion}

Achieving long-term suppression of possum populations requires development of innovative long-term control tools. This study successfully demonstrated the use of a new resetting delivery system for controlling possums. A sequence of research steps were completed from initial formulation of a toxic gel through to a short-term, proof-of-concept field trial.

Pen and field trial results from this study showed that possums triggered the resetting delivery systems, and grooming behaviour commenced shortly after a measured dose of toxin had been dispensed. Results from previous trials using paste and hard baits (Eason et al. 2013) have shown that zinc phosphide is fast-acting when delivered at toxic doses to possums, with clinical signs first appearing from $15 \mathrm{~min}$, and death after a lethal dose generally occurring in 3-5 hours. Times to death in the trials reported here (minimum 1.5 hours; average 4.6 hours) are likely to be over-estimates, as possums were checked only hourly (to avoid influencing behaviour during the trial) and actual time of death was difficult to estimate via video. Even so, these comparatively short times to death due to zinc phosphide provide animal welfare benefits compared with many current possum control tools, for example 11.5 hours for sodium fluoroacetate (1080), 9 days for cholecalciferol and 21 days for brodifacoum (Eason et al. 2011).

Almost $90 \%$ of our collared possums were killed by the RDS units during the small-scale field trial. We assume that these results are representative of a larger population reduction occurring at the site. Similarly, reductions in possum populations of up to $92 \%$ have been achieved in large-scale trials with zinc phosphide in conventional bait stations (Eason et al. 2013).

The RDS units have the additional advantages of increased non-target safety and longer-term deployment capabilities, compared with conventional control methods of trapping, aerial bait delivery and bait stations. Reducing the potential risks to non-target species was a key focus of the design process, and the device was designed so that it is highly unlikely that any species indigenous to New Zealand would be able to trigger the units. This is particularly important for birds such as kiwi (Apteryx spp.) and weka (Gallirallus australis), both of which can be at risk with other control methods.
At this stage in the development process, it is difficult to estimate how long the device will be able to remain in the field before requiring servicing. Each device will contain enough toxin for 50-100 doses and power usage is very low. Currently, it is estimated that a RDS device will be able to be left in situ for at least 6 months before servicing is required. Unlike traditional bait station designs, the RDS units protect stored toxins from weathering or bait degradation, and are likely to be considerably more robust over longer periods of time. Recently, new long-life lures for possums have been developed(Linklater et al. 2013, MacKay et al.2014), allowing the device to remain attractive to possums for 6 months or longer without requiring lure replacement.

The results achieved in our small-scale field trial have provided confidence to proceed to the next stage, which will include a larger-scale, longer-term field trial in Abel Tasman National Park. Current work is also focused on the cost-effectiveness of these devices and optimal placement in the landscape; for example, if there is potential for possums to begin reinvading from surrounding areas over time (as demonstrated in our trial by the movement of two individuals from the pine shelter belt area), then placing one device per 2-5 ha may suffice. This reduced density of devices would make systems substantially more cost-effective, especially given their predicted low maintenance requirements.

This new tool shows potential for providing sustained maintenance control of possum populations, and may have scope for preventing reinvasion of areas after local possum eradication. Future trials are scheduled over the next 12-18 months, first to confirm the effectiveness of the RDS, and then to evaluate their ability to continuously suppress possum populations for periods of greater than 12 months over large areas (i.e. $>100$ ha). The effectiveness of RDS units at preventing reinvasion will also be explored, by placing them in buffer-zones around the periphery of farmland and conservation areas that have been cleared of possums. Additional research foci will be the cost-effectiveness of these devices (especially given their lack of required maintenance) and their optimal spatial layout across the landscape.

\section{Acknowledgements}

Financial support for this research was supplied by the Ministry of Business, Innovation and Employment and Connovation Ltd. All procedures were approved by the Lincoln University Animal Ethics Committee (approval numbers AEC 400 and 414), and complied with all current New Zealand laws. James Russell assisted with statistical analysis and the comments of several anonymous reviewers greatly improved this manuscript.

\section{References}

Blackie H, MacKay J, Allen W, Smith D, Barrett B, Whyte B, Murphy E, Ross J, Shapiro L, Ogilvie S, Sam S, MacMorran D, Inder S, Eason CT 2014. Innovative developments for long-term mammalian pest control. Pest Management Science 70: 345-351.

Coleman JD, Caley P 2000. Possums as a reservoir of Bovine Tb. In: Montague TL ed. The brushtail possum: biology, impact and management of an introduced marsupial. Lincoln, Manaaki Whenua Press. Pp. 92-104. 
Cowan PE 2005. Brushtail possum. In: King CM ed. The handbook of New Zealand Mammals. 2nd edn. Melbourne, Oxford University Press. Pp. 56-80.

Eason CT, Spurr EB 1995. Review of the toxicity and impacts of brodifacoum on non-target wildlife in New Zealand. New Zealand Journal of Zoology 22: 371-379.

Eason CT, Fagerstone KA, Eisemann JD, Humphrys S, O'Hare JR, Lapidge SJ 2010. A review of existing and potential New World and Australasian vertebrate pesticides with a rationale for linking use patterns to registration requirement. International Journal of Pest Management 56: $109-125$

Eason C, Miller A, Ogilvie S, Fairweather A 2011. An updated review of the toxicology and ecotoxicology of sodium fluoroacetate (1080) in relation to its use as a pest control tool in New Zealand. New Zealand Journal of Ecology 35: $1-20$.

Eason C, Ross J, Blackie H, Fairweather A 2013. Toxicology and ecotoxicology of zinc phosphide as used for pest control in New Zealand. New Zealand Journal of Ecology 37: $1-11$.

Fisher P 1999. Review of using Rhodamine B as a marker for wildlife studies. Wildlife Society Bulletin 27: 318-329.

Fitzgerald G, Wilkinson R, Saunders L 2000. Public perceptions and issues in possum control. In: Montague TL ed. The brushtail possum: biology, impact and management of an introduced marsupial. Lincoln, Manaaki Whenua Press. Pp. 187-197.

Henderson RJ, Frampton CM, Morgan DR, Hickling GJ 1999. Efficacy of baits containing 1080 for the control of captive brushtail possums. Journal of Wildlife Management 63: 1138-1151.

Hickling GJ, Henderson RJ, Thomas MC 1999. Poisoning mammalian pests can have unintended consequences for future control: two case studies. Journal of Ecology 23: 267-273.

Ji W, Sarre SD, White PLC, Clout MN 2004. Population recovery of common brushtail possums after local depopulation. Wildlife Research 31: 543-550.

Editorial board member: Deb Wilson

Received 17 July 2014; accepted 27 May 2015
Linklater W, Greenwood D, Keyzers RA, Duckworth J. Banks P, MacKay JWB, Stockum C 2013. Pied-pipers wanted: The search for super-lures of New Zealand mammal pests. New Zealand Science Review 70: 31-36.

MacKay JM, Waters J, Blackie H 2014. Field trials of novel lures for possum control. Connovation Ltd Internal Report. Pp. 1-9.

McDonald R, Short J-A, Cate L, Lyall K, Orchard R 1999. New technology for poison delivery. New Zealand Journal of Ecology 23: 289-292.

Morgan D 1999. Risks to non-target species from use of a gel bait for possum control. New Zealand Journal of Ecology 23: 281-287.

Morgan DR, Hickling GJ 2000. Techniques used for poisoning possums. In: Montague TL ed. The brushtail possum: biology, impact and management of an introduced marsupial. Lincoln, Manaaki Whenua Press. Pp. 143-153.

Morgan DR, Morris G, Hickling GJ 1996. Induced 1080 baitshyness in captive brushtail possums and implications for management. Wildlife Research 23: 207-211.

Morris G, Warburton B, Cross M.L, Nugent G 2012. Hoarding behaviour by ship rats (Rattus rattus) in captivity and its relevance to the effectiveness of pest control operations. European Journal of Wildlife Research 58: 483-488.

O'Connor CE, Matthews LR 1995. Cyanide induced aversions in the possum (Trichosurus vulpecula): Effect of route of administration, dose, and formulation. Physiology and Behaviour 58: 265-271.

Payton I 2000. Damage to native forests. In: Montague TL ed. The brushtail possum: biology, impact and management of an introduced marsupial. Manaaki Whenua Press, Lincoln, New Zealand. Pp 111-125.

Ross JG, Hickling GJ, Morgan DR, Eason CT 2000. The role of non-toxic prefeed and postfeed in the development and maintenance of 1080 bait shyness in captive brushtail possums. Wildlife Research 27: 69-74.

Thomas MD 1994. Possum control in native forest using sodium monofluoroacetate (1080) in bait stations. Proceedings of the New Zealand Plant Protection Conference 47: 256-259. 